\title{
Space occupying lesions of central nervous system: A radiological-histopathological correlation study
}

\author{
Sunila ${ }^{1}$, Kumarguru. B.N. ${ }^{2, *}$, T S Vasan ${ }^{3}$, Manjunath. G.V. ${ }^{4}$ \\ ${ }^{\mathbf{1}}$ Former Professor, ${ }^{\mathbf{2}}$ Associate Professor, ${ }^{\mathbf{3}}$ Professor and Head, ${ }^{\mathbf{4}}$ Vice-Prinicpal, Former Professor and HOD, ${ }^{\mathbf{1 , 2}, \mathbf{4}}$ Dept. of \\ Pathology, ${ }^{3}$ Dept. of Neurosurgery, ${ }^{1,3,4}$ JSS Medical College, Mysore, Karnataka, ${ }^{2}$ P.E.S. Institute of Medical Sciences and \\ Research, Kuppam, Andhra Pradesh, India
}

*Corresponding Author:

Email: kumarguru1978@yahoo.com

Received: $16^{\text {th }}$ October, 2017

Accepted: $07^{\text {th }}$ February, 2018

\begin{abstract}
Introduction: Radiological imaging modalities are important pre-operative diagnostic tools to detect the central nervous system [CNS] lesion. Radiological findings can be used by pathologists to narrow down the differential diagnoses. Radiological diagnosis requires confirmation by histopathology

Aims: 1 . To study various patterns of central nervous system [CNS] lesions in histopathology.

2. To correlate radiological diagnosis with histopathological diagnosis.

3. To evaluate the diagnostic efficacy of radiological diagnosis.

Settings and Study Design: Analytical study at tertiary care hospital.

Materials and Methods: Eighty eight cases were analyzed. Histopathological evaluation was done from biopsy samples sent in formalin. Tissue processing was done by standard operating procedure. Tissue sections were routinely stained by H\&E. Special stains were performed in selected cases. Radiological diagnosis was correlated with histopathological diagnosis and concordance was calculated.

Statistical Analysis: Frequencies, Chi-Square Test and Crosstabs were used for calculation.

Results: Histopathological diagnosis of eighty eight cases included neoplastic lesions [90.9\%] and non-neoplastic lesions [9.09\%]. Correct diagnosis was achieved by radiology in 36 cases [45\%] by complete concordance. However, diagnostic accuracy improved considerably [85\%] after applying partial concordance criteria. For the detection of neoplastic lesions, radiological diagnosis had sensitivity of $96.25 \%$, specificity of $50 \%$ and efficacy of $92.04 \%$. The p value, determining efficacy of radiological investigations for detecting CNS neoplasms was statistically significant $[\mathrm{p}<0.005]$.

Conclusions: Radiological investigation is a reliable diagnostic tool for space occupying central nervous system lesions. It has high sensitivity and is highly efficacious investigative modality.
\end{abstract}

Keywords: Biopsy, Neoplasms, Tissue.

\section{Introduction}

Space occupying lesions [SOLs] of Central Nervous System [CNS] are important cause of neurological morbidity and mortality. ${ }^{1,2}$ SOLs may be neoplastic or non-neoplastic. ${ }^{1}$ They may follow a serious clinical course even when they are inflammatory lesions or benign neoplasms. ${ }^{2}$ Early diagnosis is necessary to plan appropriate intervention. Radiological investigative modalities like computed tomography $[\mathrm{CT}]$ and Magnetic resonance Imaging [MRI] are important preoperative diagnostic tools to detect the lesion. ${ }^{1}$

Interpretation of histopathology of CNS tumors is significantly aided when viewed in perspective of clinical, per-operative and radiological findings. Radiological imaging is an important component of diagnosis and planning treatment. ${ }^{3}$ Radiological findings can be used by pathologists to narrow down the differential diagnoses. ${ }^{4}$ However, radiological diagnosis of SOL requires confirmation by histopathology. Radiological investigation is supportive for an accurate histopathological diagnosis. Hence, histopathology considered as gold standard for diagnosis of CNS lesions. ${ }^{2}$

Since brain biopsy is an invasive procedure, every effort should be made to establish an accurate diagnosis pre-operatively. Treatments strategies differ from one type of brain neoplasm to another type. ${ }^{5}$ Majority of the patients have fairy characteristic presentation. However, many patients with intracranial lesions may have atypical presentation secondary to intra-tumoral haemorrhage, arterial occlusion, cerebral infarction or tumor involvement of silent areas. Such lesions pose a diagnostic challenge and needs pre-operative radiological evaluation. ${ }^{6}$ The present study was undertaken to find out the concordance between Radiological diagnosis and histopathological diagnosis and determine the diagnostic efficacy of radiological investigation.

\section{Materials and Methods}

The study was conducted in the department of pathology from January 2010 to September 2012 for a period of two years and eight months. It was an 
analytical type of study. Eighty eight cases were analysed.

Inclusion Criteria: All neurosurgical cases for histopathological examination were performed and preoperative radiological [CT scan or MRI or both] diagnosis was available.

Exclusion Criteria: Those neurosurgical cases in which histopathological was inconclusive, those cases in which subsequent histopathological examination was not performed; and those cases in which radiological diagnosis was not available

Tissue samples sent in $10 \%$ formalin were allowed to fix for 24 hours. Gross examination was done and bits were given. Paraffin embedded sections were routinely stained by $\mathrm{H} \& \mathrm{E}$. Special stains [PAS, reticulin] were employed in selected cases.

Radiological diagnosis [CT scan or MRI] was compared with that of histopathology. When both CT scan and MRI diagnosis was available, MRI diagnosis was considered for concordance. Available clinical details, radiological and laboratory investigation data were documented. All primary CNS tumors were histologically categorised according to 2007 WHO [World Health Organization] classification. ${ }^{7}$ Those lesions not included under WHO classification were categorised as unclassified lesions.

Statistical Analysis: Frequencies, Chi-Square Test and Crosstabs were used for calculation. Radiological diagnosis was compared with histopathological diagnosis and the diagnostic efficacy of radiological investigation was evaluated. All statistical calculations were done through statistical software STATA version 13.

\section{Results}

Eighty eight cases were analyzed. The CNS lesions ranged from $1 \mathrm{yr}$ to $75 \mathrm{yr}$. Lesions were most common in seventh decade [mean $=45.07 \mathrm{yr}$ ]. Females were affected in majority of cases [59.09\%] with M:F ratio of $1: 1.4$. CNS lesions were more common in intracranial region [84.09\%] than spinal cord region [15.90\%]. Frontal region [24.32\%] was the most common intracranial site of involvement. Thoracic region [85.71\%] was the most common site of involvement in the spinal cord region.

Out of 88 cases, 80 cases [90.9\%] were neoplastic lesions constituting the majority and eight cases [9.09\%] were non-neoplastic lesions. The distribution of various neoplastic and non-neoplastic CNS lesions and their diagnostic accuracies are enumerated in Table 1. Among the neoplastic lesions, neuroepithelial tumors $(32.95 \%)$ constituted most common tumor. Lymphoma $(1.13 \%)$ and chordoma (1.13\%) constituted least common tumors.

The diagnostic accuracy was $45.45 \%$ by complete concordance and increased to $82.95 \%$ on applying partial concordance criteria. Neoplastic lesions showed better concordance than non-neoplastic lesion. Among neoplastic lesions, the metastatic tumors, haematopoeitic tumor, chordoma, meningial tumors, cranial and paraspinal nerve tumors showed better concordance than pituitary neoplasms and neuroepithelial tumors. But sellar tumor showed poor concordance. Among non-neoplastic lesions, cystic lesions and vascular lesion showed better concordance than inflammatory lesions. But necrotic lesion [Infarction] showed poor concordance. [Table 1]

Table 1: Diagnostic accuracy of CNS lesions

\begin{tabular}{|l|l|c|c|c|}
\hline S. No & Histopathology & Cases [n=88] & DACC & DAPC \\
\hline & Neoplastic lesions & $80[90.9 \%]$ & $36[45 \%]$ & $68[85 \%]$ \\
\hline 1 & Neuroepithelial tumors & $29[32.95 \%]$ & $4[13.79 \%]$ & $22[75.86 \%]$ \\
\hline & Astrocytic tumors & $19[21.59 \%]$ & $2[10.52 \%]$ & $14[73.68 \%]$ \\
\hline & Embryonal tumors & $4[4.54 \%]$ & $1[25 \%]$ & $2[50 \%]$ \\
\hline & Oligodendroglial tumor & $1[1.13 \%]$ & 0 & $1[100 \%]$ \\
\hline & Ependymal tumor & $3[3.4 \%]$ & $1[33.33 \%]$ & $3[100 \%]$ \\
\hline & Oligoastrocytic tumor & $1[1.13 \%]$ & 0 & $1[100 \%]$ \\
\hline & Neuronal and mixed neuronal tumor & $1[1.13 \%]$ & 0 & $1[100 \%]$ \\
\hline 2 & Ganglioglioma] & & & \\
\hline & Meningial tumors & $20[22.72 \%]$ & $15[75 \%]$ & $19[95 \%]$ \\
\hline & Meningotheliomatous meningioma & $9[10.22 \%]$ & $7[77.77 \%]$ & $9[100 \%]$ \\
\hline & Fibroblastic meningioma & $3[3.4 \%]$ & $3[100 \%]$ & $3[100 \%]$ \\
\hline & Transitional meningioma & $2[2.27 \%]$ & $2[100 \%]$ & $2[100 \%]$ \\
\hline & Psammomatous meningioma & $2[2.27 \%]$ & $2[100 \%]$ & $2[100 \%]$ \\
\hline & Hemangioblastoma & $1[1.13 \%]$ & $1[100 \%]$ & $1[100 \%]$ \\
\hline & Atypical meningioma & $1[1.13 \%]$ & 0 & $1[100 \%]$ \\
\hline & Angiomatous meningioma & $1[1.13 \%]$ & 0 & 0 \\
\hline 3 & Hemangiopericytoma & $1[1.13 \%]$ & 0 & $1[100 \%]$ \\
\hline & Cranial and paraspinal nerve tumors & $15[17.04 \%]$ & $10[66.66 \%]$ & $14[93.33 \%]$ \\
\hline & Schwannoma & $14[15.9 \%]$ & $9[64.28 \%]$ & $13[92.85 \%]$ \\
\hline
\end{tabular}




\begin{tabular}{|l|l|c|c|c|}
\hline & Neurofibroma & $1[1.13 \%]$ & $1[100 \%]$ & $1[100 \%]$ \\
\hline 4 & Pituitary neoplasm & $7[7.95 \%]$ & $5[71.42 \%]$ & $6[85.71 \%]$ \\
\hline 5 & Metastatic tumors & $5[5.68 \%]$ & $2[40 \%]$ & $5[100 \%]$ \\
\hline & Adenocarcinoma & $4[4.54 \%]$ & $2[50 \%]$ & $4[100 \%]$ \\
\hline & Squamous cell carcinoma & $1[1.13 \%]$ & 0 & $1[100 \%]$ \\
\hline 6 & Sellar tumors & $2[2.27 \%]$ & 0 & 0 \\
\hline & $\begin{array}{l}\text { Adamantinomatous } \\
\text { craniopharyngioma }\end{array}$ & $2[2.27 \%]$ & 0 & 0 \\
\hline 7 & Lymphoma and haematopoietic tumors & $1[1.13 \%]$ & 0 & $1[100 \%]$ \\
\hline & High grade lymphoma & $1[1.13 \%]$ & 0 & $1[100 \%]$ \\
\hline 8 & Unclassified tumor & $1[1.13 \%]$ & 0 & $1[100 \%]$ \\
\hline & Chordoma & $1[1.13 \%]$ & 0 & $1[100 \%]$ \\
\hline & Non-neoplastic lesions & $8[9.09 \%]$ & $4[50 \%]$ & $5[62.50 \%]$ \\
\hline 1 & Cystic lesions & $3[3.4 \%]$ & $3[100 \%]$ & $3[100 \%]$ \\
\hline & Rathke cyst & $1[1.13 \%]$ & $1[100 \%]$ & $1[100 \%]$ \\
\hline & Epidermoid cyst & $2[2.27 \%]$ & $2[100 \%]$ & $2[100 \%]$ \\
\hline 2 & Inflammatory lesions & $3[3.4 \%]$ & $1[33.33 \%]$ & $1[33.33 \%]$ \\
\hline & Tuberculoma & $2[2.27 \%]$ & $1[50 \%]$ & $1[50 \%]$ \\
\hline & Acute inflammatory lesion & $1[1.13 \%]$ & 0 & 0 \\
\hline 3 & Vascular lesions & $1[1.13 \%]$ & 0 & $1[100 \%]$ \\
\hline & Arterio-venous malformation & $1[1.13 \%]$ & 0 & $1[100 \%]$ \\
\hline 4 & Unclassified & $1[1.13 \%]$ & 0 & 0 \\
\hline & Necrotic lesion & $1[1.13 \%]$ & 0 & 0 \\
\hline & Total & 88 & $40[45.45 \%]$ & $73[82.95 \%]$ \\
\hline
\end{tabular}

DACC: Diagnostic Accuracy by Complete Concordance

DAPC: Diagnostic Accuracy after Considering Partial Concordance

The term "Complete concordance" was applied to the cases in which radiological diagnosis was exactly identical to the final histopathological diagnosis. "Partial concordance" was applied to cases in which radiological diagnosis showed minor deviation from final histopathological diagnosis but the lesion belong to the same category or one of the radiological differential diagnoses matches with final histopathological diagnosis. "Discordance" was considered in cases where radiological diagnosis differed significantly from the final histological diagnosis with respect WHO grades and/or CNS lesion categories.

Primary CNS neoplasms were categorized according to WHO grades and their diagnostic accuracies are enumerated in Table 2. WHO Grade I tumors constituted the most common primary neoplastic CNS lesion. WHO grade III tumors constituted the least common primary neoplastic lesion.
The diagnostic accuracy was $43.93 \%$ by complete concordance and increased to $72.72 \%$ on applying partial concordance criteria. Concordance was better in WHO grade II and WHO grade I than WHO grade III. Concordance was relatively poor in WHO grade IV. [Table 2]

Table 2: Diagnostic accuracy in WHO grades of primary neoplastic lesions of CNS

\begin{tabular}{|l|c|c|c|c|}
\hline S. No & $\begin{array}{c}\text { Who Grades of Primary CNS } \\
\text { Neoplasms }\end{array}$ & $\begin{array}{c}\text { Cases } \\
{[\mathbf{n = 6 6}}\end{array}$ & DACC & DAPC \\
\hline 1 & Grade I & $42[63.63 \%]$ & $26[61.90 \%]$ & $33[78.57 \%]$ \\
\hline 2 & Grade II & $9[13.63 \%]$ & $1[11.11 \%]$ & $8[88.88 \%]$ \\
\hline 3 & Grade III & $2[3.03 \%]$ & 0 & $1[50 \%]$ \\
\hline 4 & Grade IV & $13[19.69 \%]$ & $2[15.38 \%]$ & $6[46.15 \%]$ \\
\hline & Total & 66 & $29[43.93 \%]$ & $48[72.72 \%]$ \\
\hline
\end{tabular}

DACC: Diagnostic Accuracy by Complete Concordance

DAPC: Diagnostic Accuracy after Considering Partial Concordance

The Statistical values were calculated by Galen and Gambino method. For the detection of neoplastic lesions, radiological diagnosis had 77 true positive cases, four false positive cases, three false negative cases, four true negative cases, sensitivity of $96.25 \%$, specificity of $50 \%$, false positive error rate of $4.54 \%$, false negative error rate of $3.4 \%$, positive predictive value of $95.06 \%$, negative predictive value of $57 \%$ and diagnostic efficacy of $92.04 \%$. The $\mathrm{p}$ value, determining efficacy of radiological diagnosis for detecting CNS neoplasms was statistically significant $[\mathrm{p}<0.005]$. 


\section{Discussion}

Histopathology is considered as the gold standard investigation for the evaluation of CNS lesions. Radiological investigation is the only means for preoperative assessment. Radiological techniques help to localize CNS lesions and plan surgery. Radiological diagnosis of SOL requires confirmation by histopathology. ${ }^{2}$ Space occupying lesions of CNS have a wide spectrum of histopathological patterns. The present study emphasizes the significance of correlation between pre-operative radiological diagnosis and histopathological diagnoses.

Dogar T et $\mathrm{al}^{2}$ and Goyani BR et $\mathrm{al}^{8}$ observed that most of the cases were seen in fourth decade in their study. Kaki RR et $\mathrm{al}^{9}$ documented that CNS lesions were common in fifth decade in their study. In contrast to the other studies, the present study showed clustering of cases in the seventh decade. Jindal $\mathrm{N}$ et al, ${ }^{1}$ Dogar T et al, ${ }^{2}$ Goyani BR et $\mathrm{al}^{8}$ and Tesfay $\mathrm{M}$ et $\mathrm{al}^{10}$ observed male predominance in their study. In contrast, Kaki RR et $\mathrm{al}^{9}$ and the present study showed female predominance in their study. In the studies conducted by Dogar $\mathrm{T}$ et al, ${ }^{2}$ Goyani BR et al ${ }^{8}$ and Kaki RR et al, ${ }^{9}$ parietal region was the most common site of involvement of CNS lesions. In contrast, Jindal $\mathrm{N}$ et $\mathrm{al}^{2}$ and the present study documented frontal region as the most common site of involvement of CNS lesions.

The distribution pattern of various CNS lesions in the present study was compared with other studies. In all the studies, neoplastic lesions were more common than non-neoplastic lesions. Among neoplastic lesions, neuroepithelial tumors were commonest followed by meningeal tumors. Dogar $\mathrm{T}$ et $\mathrm{al}^{2}$ and Pant $\mathrm{I}$ et $\mathrm{al}^{4}$ documented similar observations in their studies. In contrast, Kaki RR et al, ${ }^{9}$ Tesfay $\mathrm{M}$ et al ${ }^{10}$ and Mahmoud $\mathrm{MZ}$ et $\mathrm{al}^{11}$ found meningel tumor as the commonest neoplastic lesion in their study. Haemopoetic tumors were least common neoplastic lesion in the present study. Pant $\mathrm{I}$ et $\mathrm{al}^{4}$ and Tesfay $\mathrm{M}$ et $\mathrm{al}^{10}$ documented similar observation in their study. Among nonneoplastic lesions, Cystic lesions were the most common lesion in most of the studies except Dogar T et $\mathrm{al}^{2}$ in which inflammatory lesion was commonest nonneoplastic lesion. [Table 3]

Table 3: Comparison of distribution of various space occupying lesions of CNS

\begin{tabular}{|c|c|c|c|c|c|c|c|c|c|c|c|c|c|}
\hline $\begin{array}{l}\dot{z} \\
\dot{s}\end{array}$ & 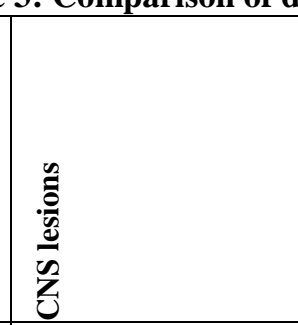 & 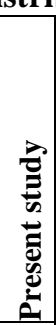 & 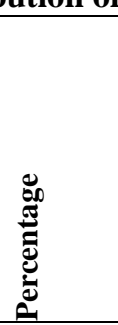 & 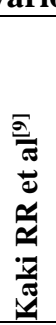 & 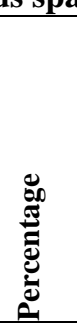 & 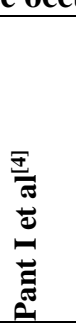 & 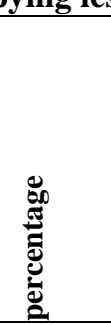 & 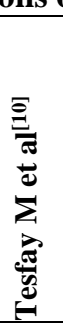 & 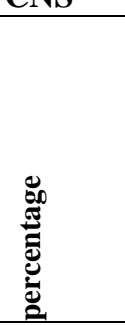 & 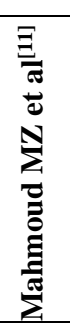 & 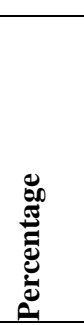 & 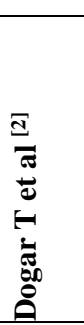 & 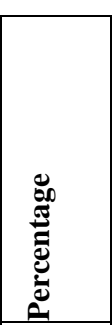 \\
\hline 1 & $\begin{array}{l}\text { Neuroepithelial } \\
\text { tumors }\end{array}$ & 29 & $32.95 \%$ & 14 & $28 \%$ & 100 & $49.01 \%$ & 15 & $15.62 \%$ & 0 & 0 & 48 & $47.05 \%$ \\
\hline 2 & Meningial tumors & 20 & $22.72 \%$ & 17 & $34 \%$ & 44 & $21.56 \%$ & 38 & $39.58 \%$ & 38 & $38 \%$ & 18 & $17.64 \%$ \\
\hline 3 & $\begin{array}{l}\text { Cranial and paraspinal } \\
\text { nerve tumors }\end{array}$ & 15 & $17.04 \%$ & 3 & $6 \%$ & 26 & $12.74 \%$ & 1 & $1.04 \%$ & 0 & 0 & 8 & $7.84 \%$ \\
\hline 4 & Pituitary neoplasm & 7 & $7.95 \%$ & 3 & $6 \%$ & 0 & 0 & 14 & $14.58 \%$ & 27 & $27 \%$ & 9 & $8.82 \%$ \\
\hline 5 & Metastatic tumors & 5 & $5.68 \%$ & 3 & $6 \%$ & 10 & $4.9 \%$ & 3 & $3.12 \%$ & 7 & $7 \%$ & 1 & $0.98 \%$ \\
\hline 6 & Sellar tumors & 2 & $2.27 \%$ & 0 & 0 & 19 & $9.31 \%$ & 0 & 0 & 0 & 0 & 3 & $2.94 \%$ \\
\hline 7 & $\begin{array}{l}\text { Lymphoma and } \\
\text { haematopoietic } \\
\text { tumors }\end{array}$ & 1 & $1.13 \%$ & 0 & 0 & 5 & $2.45 \%$ & 1 & $1.04 \%$ & 0 & 0 & 0 & 0 \\
\hline 8 & Germ cell tumors & 0 & 0 & 0 & 0 & 0 & 0 & 0 & 0 & 1 & $1 \%$ & 0 & 0 \\
\hline 9 & Unclassified tumors & 1 & $1.13 \%$ & 0 & 0 & 0 & 0 & 2 & $2.08 \%$ & 0 & 0 & 1 & $0.98 \%$ \\
\hline 10 & Cystic lesions & 3 & $3.4 \%$ & 6 & $12 \%$ & 0 & 0 & 14 & $14.58 \%$ & 0 & 0 & 4 & $3.92 \%$ \\
\hline 11 & Inflammatory lesions & 3 & $3.4 \%$ & 4 & $8 \%$ & 0 & 0 & 8 & $8.33 \%$ & 22 & $22 \%$ & 10 & $9.8 \%$ \\
\hline 12 & Vascular lesions & 1 & $1.13 \%$ & 0 & 0 & 0 & 0 & 0 & 0 & 5 & $5 \%$ & 0 & 0 \\
\hline 13 & Unclassified & $\overline{1}$ & $1.13 \%$ & 0 & 0 & 0 & 0 & 0 & 0 & 0 & 0 & 0 & 0 \\
\hline & Total cases & 88 & & 50 & & 204 & & 96 & & 100 & & 102 & \\
\hline
\end{tabular}

Out of 88 cases, 15 cases [17.05\%] were misdiagnosed [Discordant]. Misdiagnosed cases and probable cause are summarized in Table 4. The reasons for misdiagnosis were mainly radiological similarity of the lesions and interfering factors like presence of haemorrhage, necrosis and edema. Pant I et $\mathrm{al}^{4}$ had also analysed misdiagnosed cases in their study. Similar to the present study, Pant I et $\mathrm{al}^{4}$ had documented that low grade astrocytoma and medulloblastomas were misdiagnosed as ependymoma. Low grade astrocytoma and ependymoma may be considered as close 
differentials depending on the location. Medulloblastomas was misdiagnosed as ependymoma because of areas of haemorrhage and infiltrative growth pattern in their study. ${ }^{4}$ One case of angiomatous meningioma was misdiagnosed as cystic glioma because of solid cystic nature and increased vascularity of the lesion. Tesfay $\mathrm{M}$ et $\mathrm{al}^{10}$ opined and concluded in their study that varying degree of perilesional lesional edema seen in meningioma is also a feature of gliomas, metastasis and infection. Iwama et al mention that signal intensities of gliomas on MRI did not correlate with the malignancy of the tumor. Tovi et al concluded in their study that though the degree of malignancy of the lesion as a whole can be assessed by MRI, it does not allow gliomas to be clearly delineated. ${ }^{4}$

Table 4: Discordant cases of CNS lesions

\begin{tabular}{|c|c|c|c|c|}
\hline S. No & Histopathology & $\begin{array}{c}\text { Discordant } \\
\text { cases }\end{array}$ & Radiological diagnosis & $\begin{array}{c}\text { Probable causes for mis- } \\
\text { diagnosis }\end{array}$ \\
\hline & Neoplastic Lesions & & & \\
\hline & Neoplastic lesions & $12[15 \%]$ & & \\
\hline 1 & Neuroepithelial tumors & $7[24.13 \%]$ & & \\
\hline \multirow[t]{6}{*}{$\mathrm{A}$} & Astrocytic tumors & $5[26.31 \%]$ & & \\
\hline & Glioblastoma & $2[28.57 \%]$ & 1. Haemorrhagic lesion & $\begin{array}{c}\text { Vacularity of the lesion and } \\
\text { haemorrhage }\end{array}$ \\
\hline & & & 2. Metastasis & $\begin{array}{l}\text { Involvement of left temporal and } \\
\text { parietal lobe and Similar features }\end{array}$ \\
\hline & Pilocytic astrocytoma & $2[50 \%]$ & 1. Malignant tumor & $\begin{array}{l}\text { Heterogeneous nature of the } \\
\text { lesion and mass effect }\end{array}$ \\
\hline & & & $\begin{array}{l}\text { 2. Pituitary adenoma/ } \\
\text { Craniopharyngioma }\end{array}$ & Unusual Location of the tumor \\
\hline & Fibrillary astrocytoma & $1[50 \%]$ & $\begin{array}{c}\text { Medulloblastoma/ } \\
\text { Ependymoma with } \\
\text { obsructive hydrocephalus }\end{array}$ & $\begin{array}{c}\text { Presentation as ill-defined } \\
\text { nodular lesion with mass effect } \\
\text { and location near fourth ventricle }\end{array}$ \\
\hline \multirow[t]{3}{*}{$\mathrm{B}$} & Embryonal tumor & $2[50 \%]$ & & \\
\hline & Anaplastic medulloblastoma & $1[50 \%]$ & Ependymoma & $\begin{array}{l}\text { Similar features of the lesion and } \\
\text { location }\end{array}$ \\
\hline & $\begin{array}{c}\text { Primitive neuroectodermal } \\
\text { tumor }\end{array}$ & $1[100 \%]$ & Meningioma & $\begin{array}{c}\text { Lobulated nature of the lesion } \\
\text { with mass effect }\end{array}$ \\
\hline \multirow[t]{2}{*}{2} & Meningial tumors & $1[5 \%]$ & & \\
\hline & Angiomatous meningioma & $1[100 \%]$ & Cystic glioma & $\begin{array}{c}\text { Solid-cystic nature and increased } \\
\text { vascularity of the lesion }\end{array}$ \\
\hline \multirow[t]{2}{*}{3} & $\begin{array}{c}\text { Cranial and paraspinal nerve } \\
\text { tumors }\end{array}$ & $1[6.66 \%]$ & & \\
\hline & Schwannoma & $1[7.14 \%]$ & Meningioma & Similar radiological features \\
\hline 4 & Pituitary neoplasm & $1[14.28 \%]$ & Rathke cleft cyst & Cystic nature, similar location \\
\hline \multirow[t]{5}{*}{5} & Sellar tumors & $2[100 \%]$ & & \\
\hline & $\begin{array}{l}\text { Adamantinomatous } \\
\text { craniopharyngioma }\end{array}$ & $2[100 \%]$ & $\begin{array}{c}\text { 1. Pituitary } \\
\text { macroadenoma/ } \\
\text { Haemangioma } \\
\end{array}$ & Similar location of the lesion \\
\hline & & & 2. Third ventricle cyst & $\begin{array}{c}\text { Similar location and cystic nature } \\
\text { of the lesion }\end{array}$ \\
\hline & Non-Neoplastic Lesions & & & \\
\hline & Non-neoplastic lesions & $3[37.5 \%]$ & & \\
\hline \multirow[t]{3}{*}{1} & Inflammatory lesions & $2[66.66 \%]$ & & \\
\hline & Tuberculoma & $1[50 \%]$ & Malignant glioma & $\begin{array}{l}\text { Involvement of left frontal lobe } \\
\text { and parietal lobe and mass effect }\end{array}$ \\
\hline & Acute inflammatory lesion & $1[100 \%]$ & Pituitary macroadenoma & Similar location of the lesion \\
\hline \multirow[t]{2}{*}{2} & Unclassified & $1[100 \%]$ & & \\
\hline & Necrotic lesion & $1[100 \%]$ & Anaplastic astrocytoma & $\begin{array}{l}\text { Vasogenic edema and location of } \\
\text { the lesion in white matter of left } \\
\text { temporal lobe and parietal lobe }\end{array}$ \\
\hline
\end{tabular}

In the present study, concordance was $71.21 \%$. Pant I et $\mathrm{al}^{4}$ documented a higher concordance [96.07\%] in their study. In contrast, Dogar T et $\mathrm{al}^{2}$ observed lower concordance [68\%] in their study. In the present study, diagnostic accuracy by complete concordance [DACC] and diagnostic accuracy after applying partial concordance criteria [DAPC] was calculated. But other studies had not clearly specified 
about criteria followed to consider concordance. This may be important because, not all the cases diagnosed by radiology can perfectly match with histopathological diagnosis, which is considered as gold standard.

For the detection of meningioma, Tesfay $\mathrm{M}$ et al $^{10}$ observed sensitivity of $80 \%$ and specificity of $95 \%$. For the detection of gliomas, sensitivity was $71 \%$ and specificity was $85.7 \%$ in their study. However, overall sensitivity and specificity for detection of neoplastic lesion was not mentioned in the study. ${ }^{10}$ In the present study, for detection of neoplastic lesions by radiology, sensitivity and specificity were $96.25 \%$ and $50 \%$ respectively. In contrast, Kaki RR et $\mathrm{al}^{9}$ documented lower sensitivity [92.5\%] and higher specificity [70\%]. Similarly Jindal $\mathrm{N}$ et $\mathrm{al}^{1}$ had also documented lower sensitivity [90\%] and higher specificity [57\%]. This reflects failure to consider non-neoplastic lesion while offering radiological diagnosis in the present study.

Tesfay $\mathrm{M}$ et al ${ }^{10}$ documented diagnostic efficacy of $88.6 \%$ for meningiomas and $83 \%$ for gliomas in their study. For the detection of neoplastic lesions, the diagnostic efficacy in the present study was $92.04 \%$. Kaki RR et $\mathrm{al}^{9}$ had observed lower diagnostic efficacy [88\%] in their study. Similarly, Jindal $\mathrm{N}$ et $\mathrm{al}^{1}$ had recorded a lower diagnostic efficacy [84.2\%] in their study. In contrast, Goyani $\mathrm{BR}$ et $\mathrm{al}^{8}$ recorded a diagnostic a higher efficacy [98.57\%] because, only MRI was used as investigative modality in their study. Jindal $\mathrm{N}$ et al, ${ }^{1}$ Kaki RR et $\mathrm{al}^{9}$ and the present study used both CT and MRI as investigative modalities.

Each investigative modality has its own advantages and disadvantages. In view of low specificity of the radiological diagnosis in the present study, it may be suggested that, in addition to radiological impression, neurosurgeon can also consider other diagnostic modalities such as intra-operative squash smear cytology and intra-operative frozen section to plan or modify further management.

\section{Conclusion}

Radiological investigation is a reliable diagnostic tool for space occupying central nervous system lesions. It may be considered as an important supportive and complimentary tool to histopathological diagnosis. Radiological similarity of the lesions and presence of interfering factors are important contributory factors for diagnostic pitfalls. Radiological investigation has high sensitivity and is highly efficacious for the diagnosis of neoplastic CNS lesions. However, in view of low specificity, multimodality approach may be beneficial for management of the patient.

\section{Acknowledgement}

We sincerely thank Dr. S.M. Chandrashekara Shetty, former Professor and Head, Department of Radio-Diagnosis, JSS Medical College, JSS University, Mysore, for the kind cooperation extended to us for the work up of the cases in the present study.

\section{References}

1. Jindal N, Verma SR, Gupta PK, Mital M, "Imaging of Intracranial Space Occupying Lesion: A prospective Study in a tertiary care centre in North India" IOSR Journal of Dental and Medical Sciences (2016) 15,34-41.

2. Dogar T, Imran AA, Hasan M, Jaffar R, Bajwa R, Qureshi ID, "Space occupying lesions of central nervous system: A radiological and Histopathological Correlation" Biomedica (2015) 31,15-20.

3. Joel DS, Johnsy MJ, "A study of clinical, radiological and pathological correlation of intraspinal compressive lesions. IOSR Journal of Dental and Medical Sciences" (2016) 15, 23-31.

4. Pant I, Chaturvedi S, Jha DK, Kumari R, Parteki S, "Central nervous system tumors: Radiologic pathologic correlation and diagnostic approach" J Neurosci Rural Pract" (2015) 6, 191-7.

5. Abdul-Kasim K, Thurnher M, Puchner S, Sundgren P, "Multimodal magnetic resonance imaging increases the overall diagnostic accuracy in brain tumours: Correlation with histopathology" S Afr J Rad (2013) 17, 04-10.

6. Anadure HN, Ravindra RS, Karnappa AS, "Morphological patterns of intracranial lesions in a tertiary care hospital in North Karnataka: A clinicopathological and immunohistochemical study" J Clin Diagn Res (2016) 10, EC01-5.

7. Louis DN, Ohgaki H, Wiestler OD, Cavenee WK, eds. WHO Classification of Tumours of the Central Nervous System. Lyon, France: IARC Press (2007) pp8-11.

8. Goyani BR, Ukani BV, Naik P, Bhagat H, Vadel MK, Sheth $\mathrm{R}$, "A Study on role of MRI in intracranial space occupying lesions" Natl J Med Res (2015) 5, 18-21.

9. Kaki RR, Anuradha B, Rani BS, Rao KS, Kusumalatha P, Sathyasuneetha, "Imaging of intracranial space occupying lesions- A prospective study in a tertiary care centre- GGH, Kakinada" A.P. J Evid Based Med Healthc (2017) 4, 617-23.

10. Tesfay M, Hawaz Y, Assefa G, Abebe M, R'adiological features and postoperative histopathologic diagnosis of intracranial masses at Tikur Anbessa specialized hospital and MCM Hospital" East and Central AfrJ Surg (2013) 18, 95106.

11. Mahmoud MZ, "Intra cranial space occupying lesions in Saudi patients using computed tomography" Asian J Med Radiol Res (2013) 1, 25-8. 